\title{
NOTAS SOBRE EL GIMFERRER CRÍTICO: ACERCA DE RADICALIDADES
}

\section{Manuel RICO}

Madrid

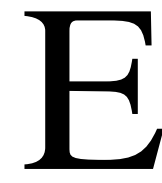
n 1971, el periodista y escritor Federico Campbell publicaba Infame turba (Campbell, 1971), una colección de entrevistas realizadas a escritores emergentes en la España que transitaba de la década de los sesenta a la de los setenta. Veintiséis autores, narradores y poetas, de dos generaciones - la emergente del 68, o grupo "novísimo" y la del 50, que iniciaba su etapa de esplendor-, entre los que se encontraba Pere Gimferrer. También se encontraban, entre los entrevistados, algunos de los escritores que ya eran o serían objeto de estudio y análisis por parte del joven Gimferrer y que entrarían a formar parte del libro de ensayos Radicalidades (Gimferrer, 1978): Juan Goytisolo, Juan Benet y Luis Goytisolo de entre los "mayores"; Leopoldo María Panero entre los jóvenes. Si establecemos una comparación entre los autores que integran Infame turba y los recogidos en la colección de ensayos citada, advertimos que, pese al filo rupturista, innovador, muy acorde con los vientos de cambio estético de aquellos años, de buena parte de los escritores coetáneos a Gimferrer (Azúa, Ana María Moix, Terenci Moix, Leopoldo María Panero, José María Guelbenzu, Antonio Martínez Sarrión o Guillermo Carnero) sólo uno, Panero, sería objeto de estudio en Radicalidades. ¿Qué cabe concluir de ello? Que su mirada sobre el panorama literario del momento, sustanciada en la colección de artículos que componen ese libro, se proyecta, ante todo, sobre autores de generaciones precedentes de las dos orillas del castellano: casi todos escritores consagrados aunque sus propuestas estéticas incorporaran significativas dosis de innovación, de ruptura; casi ninguno de entre los autores emergentes, compañeros generacionales de Gimferrer.

\section{El enfoque crítico}

$\mathrm{Su}$ enfoque crítico en aquellos años, cruciales en la evolución de la literatura en español del siglo XX, se basa en, al menos, cuatro principios: la defensa de la vanguardia 
y de las vanguardias; la concepción de estas como representación más genuina de la modernidad (para Gimferrer la modernidad está ahí y no en otro lugar); la radicalidad poética y la radicalidad política (de “izquierdas", subraya en el prólogo al libro mencionado) forman parte del impulso de subversión estética; la inexistencia de fronteras en la visión de la literatura en español, considerando de manera integrada las realidades literarias española e hispanoamericana y la de otras lenguas de España como el catalán. También responde al impulso cosmopolita que dio identidad al movimiento novísimo al cruzarse, en la mayoría de los textos de Radicalidades, los creadores europeos y norteamericanos que sirvieron de referente en la ruptura estética de finales de los sesenta/principios de los setenta: Breton, Joyce, Lautréamont, Rimbaud...

Es obvio que ese enfoque es coherente con su presencia en Nueve novísimos poetas españoles (Castellet, 1970) y con no pocas declaraciones de principios a las que hace referencia en distintos medios y foros a lo largo de aquellos años setenta. Sin embargo, no estaría completo el abanico de principios-base de la mirada crítica de Gimferrer si no aludiéramos a uno cargado de negatividad: me refiero a la crítica, radical también, al realismo dominante en los años sesenta en la literatura española.

Para tener una idea clara de esa dualidad (defensa de la vanguardia versus descalificación de la "normalidad estética" precedente), no tenemos más que acudir a sus declaraciones de la época. De un lado, la respuesta, en Infame turba, a Federico Campbell, tras recabar su opinión sobre la poesía española del momento: "Hay un espléndido poeta hasta hoy injustamente preterido: Carlos Edmundo de Ory. Por lo demás, la Generación poética de los años 50 era correcta, son gentes con oficio, pero muchos se han quedado en una mera corrección académica. Pocos han sabido renovarse. Entre ellos José Ángel Valente. Tuvo un período muy conflictivo, que me hizo temer por su futuro. Pero $E l$ inocente, que acaba de aparecer en México, es un libro muy bueno, uno de los mejores libros de la poesía española de la postguerra". Y agregaba: "Respecto a la novela española actual, me interesa Benet, las dos últimas novelas de Juan Goytisolo". De otro lado, la poética que, en 1970, incluyó en la antología generacional Nueva poesía española, preparada por el crítico Florencio Martínez Ruiz. Afirmaba Gimferrer:

Las armas de la imaginación se oxidan y la banalidad ocupa el puesto de la revelación poética. Sea "social" o "esteticista", la poesía académica -es decir, casi toda la poesía española actual- carece por completo de interés para cualquier persona con sentido común [...] La mayoría de los poetas españoles han hecho un arte -por muy adulta que sea su edadde no decir absolutamente nada, ni respecto a la realidad, ni respecto al lenguaje [...] es obvio que la mayoría de los poetas españoles no escriben nada que merezca la pena de ser leído (Martínez Ruiz, 1970). 


\section{El contenido de Radicalidades}

Por tanto, en Radicalidades se concreta esa concepción a través de ensayos y artículos de lo más diverso, casi en su totalidad publicados entre 1971 y 1977 y cuyo hilo conductor podría denominarse "elogio de la heterodoxia". El simbolismo, el surrealismo, la pintura abstracta de Tàpies (el “desvanecimiento de la noción de representación”), las distintas formas de experimentalismo ocupan un lugar preferente en las reflexiones de Gimferrer. En el libro están las heterodoxias literarias hispanoamericanas del momento, con el imprescindible referente de Octavio Paz, cuyo lugar en la poesía en castellano y en el de la crítica y la reflexión sobre la propia poesía fue (es aún hoy) foco de atención y espejo en el que mirarse de Gimferrer y al que estudia y analiza a propósito de uno de sus libros esenciales, El mono gramático, la narrativa sin narrador de Manuel Puig, hecha en la desnudez de unos diálogos de enorme carga significante, el poderoso impulso narrativo de un Carlos Fuentes que deslumbró en aquellos años con su revolucionaria La región más transparente y que combinaría en su trayectoria la narrativa más tradicional con la innovación provocadora de una obra en el límite de lo inclasificable como Terra Nostra, la poesía adscrita a la Tercera Vanguardia argentina, devota de Rimbaud o Baudelaire, de Olga Orozco; también aparecen las innovaciones y heterodoxias que marcaron la literatura de la época en España: el Juan Goytisolo que abre nuevos senderos, entre el experimento, el desafío y la irreverencia, a partir de Señas de identidad; la búsqueda de la novela total de su hermano Luis, entonces entregado a la redacción de su monumental tetralogía Antagonía, el pulso entre faulkneriano y meditativo de un Juan Benet que conmocionó la novela española con la publicación, en 1968, de Volverás a Región; la trayectoria de un narrador como Camilo José Cela, que evolucionó del realismo tremendista al radicalismo innovador de San Camilo 1936; las poéticas rupturistas, entre la estética del silencio del "nuevo" José Ángel Valente, la poesía entre concreta y visual de Brossa (la "antipoesía"), el juego para-surrealista de Carlos Edmundo de Ory, poeta relegado y exiliado de cualquier recuento generacional, y el irracionalismo oscuro, sustentado en la memoria íntima, de Leopoldo María Panero (el único coetáneo al que alude, tal y como antes señalábamos).

A estas incursiones en la obra y en la trayectoria de autores posteriores a la española generación del 27 (Octavio Paz nació en 1914 y es coetáneo a los poetas españoles de la primera generación de posguerra), Gimferrer añade incursiones en voces decisivas en la poesía de vanguardia de antes de nuestra Guerra Civil y hasta cierto punto referenciales de algunos de los nuevos caminos que se están ensayando en la lírica en castellano de los años 70: Rafael Alberti, Vicente Aleixandre ("padre" de la vanguardia que Gimferrer y parte de sus compañeros de Nueve novísimos representan), el Federico García Lorca de Poeta en Nueva York, y el creacionista Juan Larrea. 
La vanguardia teatral ocupa también un lugar en las preocupaciones crítico-estéticas de Gimferrer con la presencia (en la edición de 2000) de Francisco Nieva. A ello agrega, también en la segunda edición, la narrativa inclasificable (Gimferrer la tilda de "subversiva") del filósofo Gabriel Albiac y las heterodoxias extraterritoriales, curtidas en el exilio y en la distancia respecto a la España de los siglos XIX y XVII respectivamente, José María Blanco White y Miguel de Molinos.

La práctica totalidad de las apuestas estéticas tratadas en los ensayos y artículos de que se compone Radicalidades se corresponde con una actitud cívico-política de sus autores situada en el progresismo, o en la izquierda, confirmando así el aserto expresado por el autor en el prólogo: “Un radical es o debiera ser, un hombre de izquierdas: lo radical - es decir, lo que atañe "a la situación y a la condición”, en palabras de Aleixandresupone un proyecto vital enteramente nuevo". La excepción está en Camilo José Cela, cuya identificación con el Régimen franquista fue pública y notoria, en un Octavio Paz entonces en proceso de distanciamiento de la revolución cubana y un Gabriel Albiac que, asentado en un anarquismo radical entonces, evolucionaría hacia un anarquismo con claras derivas hacia lo que entendemos como derecha política.

\section{Algunas reflexiones en perspectiva}

Con la lente que nos concede el tiempo transcurrido desde la primera edición de Radicalidades (treinta y cinco años; trece desde la segunda), creo necesario destacar algunos aspectos contradictorios o, cuanto menos curiosos, de la mirada crítica de Pere Gimferrer.

El primero, una especial propensión a profundizar en los procesos de cambio que se producen en autores que revisan de manera radical los presupuestos iniciales de su obra. Eso ocurre con narradores como Juan Goytisolo y Luis Goytisolo, cuya estética en sus primeros títulos, a caballo del realismo social, o crítico, se trueca, mediada la década de los sesenta, en un apuesta a fondo por renovar el lenguaje narrativo y experimentar por territorios inexplorados situando el idioma al límite de sus posibilidades reveladoras (Juan Goytisolo) y la estructura y el argumento en una visión caleidoscópica, de simultaneidades y paralelismos, del artefacto novela (Luis). En ese acercamiento hay algunas afirmaciones cuestionables: así, Gimferrer señala que "Señas de identidad tenía la misión de reescribir Fin de fiesta, La resaca, Fiestas o La isla". ¿Se trata de una interpretación subjetiva o se corresponde con la voluntad real de Juan Goytisolo? De lo primero está la evidencia del texto gimferreriano; a lo segundo sólo el propio Goytisolo puede responder. A mi juicio, esa novela supone un punto de no retorno, una quiebra de la apuesta realista y social que había informado la obra de su autor desde que diera los 
primeros pasos como escritor, un pasar la página utilizando los materiales de la memoria y de la experiencia y no un intento de reescritura.

Y esa especial atención a los procesos de cambio se manifiesta, también, en la extensión y la profundidad con que Gimferrer aborda la "ruptura epistemológica" que protagoniza José Ángel Valente en su trayectoria. Valora el replanteamiento de su poética y de su estética a partir de El inocente, ratificando así los términos, antes transcritos, de su respuesta a Federico Campbell en Infame turba. Sin embargo, el punto débil de ese acercamiento a la nueva etapa de José Ángel Valente se encuentra en la descalificación global de la obra de sus coetáneos o "compañeros de generación” cuya poesía es declarada por Gimferrer, en su ensayo, "cómplice de la reacción"1. Más allá del debate que suscita la identificación entre realismo y "reacción" (con su reverso lógico: vanguardia y "revolución"), es preciso resaltar la ausencia de referencias a un poeta como Claudio Rodríguez, quien ya desde su primer libro Don de la ebriedad muestra la dimensión y la altura de su radicalidad (con la que hay no pocos parentescos estilísticos en Arde el mar, libro emblemático de Gimferrer). Lo mismo cabe señalar de un libro, publicado en 1964, de un poeta de pasado entre lo realista y lo existencial como José Hierro: me refiero a Libro de las alucinaciones (1964), un anticipo extremadamente lúcido e innovador de lo que sería, treinta y cinco años después, Cuaderno de Nueva York.

El segundo aspecto tiene que ver con algunas ausencias significativas en una colección de ensayos que tiene como eje central dibujar "cierto panorama de tendencias en la vanguardia literaria hispánica". En primer lugar, llama la atención la ausencia de Tiempo de silencio (con su corolario póstumo, Tiempo de destrucción), de Luis Martín Santos, una obra nodal en la renovación de la narrativa en castellano que, además, está cargada de radicalidad. ¿Es por la transparencia de su argumento, por el sustrato de crítica social, que enlaza con el realismo precedente, o hay razones que se derivan de la sorda pugna que se establece tras la muerte del escritor y psiquiatra navarro entre Benet y la obra de aquél y de la que se da cuenta en la biografía Vidas y muertes de Martín Santos (Lázaro, 2009), de José Lázaro?²

En segundo lugar, cabe reseñar el escaso relieve que se concede a tendencias coetáneas o precedentes a la singularidad que protagoniza Carlos Edmundo de Ory: el postismo de Chicharro, Sernesi y Gabino Alejandro Carriedo, el tremendismo surreal de Miguel Labordeta, la obra de Juan Eduardo Cirlot.

\footnotetext{
${ }^{1}$ Aunque sería objeto de otro trabajo profundizar en esa afirmación, sí parece necesario preguntarse por el grado de complicidad con la reacción de la obra de poetas como Gil de Biedma, Ángel González, Francisco Brines, Claudio Rodríguez, José Agustín Goytisolo o Carlos Barral, todos opositores al franquismo en años especialmente difíciles.

2 José Lázaro transcribe en Vidas y muertes de Martín Santos una respuesta que Juan Benet dio a Eduardo G. Rico en una entrevista aparecida en 1970 a propósito de la novela de Luis Martín Santos: "Una novela con fondo de verbena y vida de pensión, y una puñalada: es costumbrismo puro, a lo Mesonero Romanos. Además, tiene el humor confundido. La ironía, que alcanza en alguna ocasión cotas muy altas, no se mantiene a lo largo del libro".
} 
La profesora Raquel Macciuci, en su crítica a la edición de 2000 de Radicalidades, subraya algunas circunstancias contextuales que aparecen como nuevas en relación con la situación de 1978: “en España se terminó de imponer un nuevo modo de narrar conocido como "Nueva narrativa española", que abandonó los caminos de la experimentación y el vanguardismo; igualmente, en el mismo período la poesía manifestó análoga preferencia por la recuperación del sentimiento, los motivos cotidianos y la narratividad del poema" (Macciuci, 2000). Si tenemos en cuenta que Pere Gimferrer, en los años setenta, identificaba vanguardismo con modernidad, literatura experimental con "auténtica literatura" y que los poetas a los que sucedía no escribían nada "que merezca la pena de ser leído" (ver respuestas a Federico Campbell), resulta cuanto menos paradójico que en paralelo a las dos ediciones de Radicalidades se apuntara, en el panorama de la literatura en castellano, una vuelta a lo figurativo, al realismo, a la narratividad. Tanto en el campo de la novela (tres años antes de la primera edición, en 1975, se había publicado La verdad sobre el caso Savolta, de Eduardo Mendoza, una suerte de puente entre el experimentalismo y la "nueva narrativa") como en poesía, donde se producen los primeros pasos de la corriente que, aplicando el principio de la muerte del padre, tomaría el relevo al culturalismo neovanguardista que el propio Gimferrer protagonizara: la poesía figurativa, de la experiencia, la "otra sentimentalidad", una reelaboración de la poesía de los cincuenta que nuestro autor había descalificado. ¿Dónde está la paradoja?, se preguntará el lector. Pues en algo sumamente ilustrativo: en esa evolución de la novela experimental al neorrealismo narrativo de los ochenta jugará un papel esencial el propio Gimferrer como lector/directivo de una editorial emblemática como Seix Barral. Es públicamente conocido su protagonismo en el lanzamiento de libros como Luna de lobos, de Julio Llamazares, o de Beatus Ille o El invierno en Lisboa, de Antonio Muñoz Molina, libros en el reverso de la vertiente experimental del Juan Goytisolo posterior a Juan sin tierra, del Luis Goytisolo de Teoría del conocimiento o Los verdes de mayo hasta el mar o de la narrativa faulkneriana, fuertemente meditativa, de Juan Benet.

Paradojas, curiosidades tal vez, que no empañan el enorme valor que para el estudio de la literatura en castellano del siglo XX tiene la mirada que Pere Gimferrer proyecta en una de las colecciones de ensayos y artículos de mayor relieve de entre las publicadas en los últimos treinta años.

\section{Bibliografía}

CAMPBell, Federico (1971): Infame turba, Barcelona, Lumen, 1994.

CAstellet, Josep Maria (1970): Nueve novísimos poetas españoles, Barcelona, Península, 2001. 
GIMFERRER, Pere (1978): Radicalidades, Barcelona, Península, 2000.

LÁZARO, Jesús (2009): Vidas y muertes de Martín Santos, Barcelona, Tusquets.

MACCIUCI, Raquel (2000): “Crítica a Radicalidades", Orbis Tertius. Año IV, n 7, La Plata, Universidad Nacional de la Plata, 2000.

MARTínEZ RUIZ, Florencio (1971): La nueva poesía española, Madrid, Biblioteca Nueva, 1971. 